\title{
Effect of $\beta$-Cyclodextrin on the Degradation Rate of Amoxicillin in Acidic Solution
}

\author{
Shinji Hidaka, ${ }^{a}$ Tadakazu ToKumura, ${ }^{*, b}$ Kazuo Tomono, ${ }^{a}$ Toyofumi Suzuki, ${ }^{a}$ Haruhisa Ueda, ${ }^{c}$ \\ Tsuneji NAGAI, ${ }^{d}$ Masashi NAGAOKA, ${ }^{b}$ Rieko NAKANE, ${ }^{b}$ and Yoshiharu MACHIDA ${ }^{b}$ \\ ${ }^{a}$ College of Pharmacy, Nihon University, 7-1 Narashinodai 7-chome Funabashi, Chiba 274-8555, \\ Japan, ${ }^{b}$ Department of Drug Delivery Research, ${ }^{c}$ Department of Physical Chemistry, \\ School of Pharmacy and Pharmaceutical Sciences, Hoshi University, 2-4-41 \\ Ebara, Shinagawa, Tokyo 142-8501, Japan, and ${ }^{d}$ The Nagai Foundation \\ Tokyo, Hon-Komagome, Bunkyo-ku, Tokyo 113-0021, Japan
}

(Received November 16, 2009; Accepted March 4, 2010; Published online March 8, 2010)

\begin{abstract}
The formation of an inclusion complex of amoxicillin (AMX) with $\beta$-cyclodextrin $(\beta$-CD) in aqueous solution was confirmed by a solubility method and proton nuclear magnetic resonance ( $\left.{ }^{1} \mathrm{H}-\mathrm{NMR}\right)$ spectroscopy. The apparent stability constant for the inclusion complex was $10.72 \mathrm{M}^{-1}$ in water at $25^{\circ} \mathrm{C}$. The effect of $\alpha$-CD, $\beta$-CD, and $\gamma$-CD on the degradation of $\mathrm{AMX}$ in a $\mathrm{pH} 1.2$ solution at $37^{\circ} \mathrm{C}$ was investigated. $\beta$-CD and $\gamma$-CD reduced the rate of degradation. $\alpha$ $\mathrm{CD}$ had no effect. These results were consistent with those of ${ }^{1} \mathrm{H}-\mathrm{NMR}$ spectroscopy. The effect of $\beta$-CD on the degradation rate was studied in more detail. The apparent first order rate constant for the degradation of AMX in the $\mathrm{pH} 1.2$ solution at $37^{\circ} \mathrm{C}$ was $0.1121 \mathrm{~h}^{-1}\left(\mathrm{t}_{1 / 2}=6.18 \mathrm{~h}\right)$, which decreased with the addition of $\beta$-CD. The rate constants and $\mathrm{t}_{1 / 2}$ values for the concentrations of $\beta$-CD added, corresponding to molar ratios of AMX to $\beta$-CD of $1: 0.5,1: 1,1: 2,1:$ 5 , and $1: 10$, were $0.1051 \mathrm{~h}^{-1}$ and $6.59 \mathrm{~h}, 0.0992 \mathrm{~h}^{-1}$ and $6.98 \mathrm{~h}, 0.0893 \mathrm{~h}^{-1}$ and $7.76 \mathrm{~h}, 0.0697 \mathrm{~h}^{-1}$ and $9.95 \mathrm{~h}$, and $0.0509 \mathrm{~h}^{-1}$ and $13.61 \mathrm{~h}$, respectively. The activation energy for the degradation of AMX in the $\mathrm{pH} 1.2$ solution was increased from $6.9 \times 10^{4} \mathrm{~J} / \mathrm{mol}$ (AMX alone) to $8.0 \times 10^{4} \mathrm{~J} / \mathrm{mol}(\mathrm{AMX}: \beta$-CD $=1: 10$ ).
\end{abstract}

Key words_amoxicillin; $\beta$-cyclodextrin; inclusion complex; stability; acidic solution

\section{INTRODUCTION}

Amoxicillin (AMX), an oral antibiotic with a wide spectrum of antibacterial activity, has recently been used to treat Helicobacter pylori (H. pylori) infections. Following this change of usage, a drug delivery system for the eradication of $H$. pylori was reported. ${ }^{1,2)}$ AMX is unstable in an acidic solution, and so a proton pump inhibitor must be administered for the eradication. Therefore, the stabilization of AMX may increase its effect in the stomach. $\mathrm{Cy}$ clodextrins (CDs) are generally used in pharmaceutical preparations to increase stability and dissolution by forming inclusion complexes with drugs. ${ }^{3-6)}$ Several presentations regarding the stabilization of AMX using CDs have been performed ${ }^{7-9)}$ In this study, the complexation of AMX with $\beta$-CD was confirmed by a solubility method and proton nuclear magnetic resonance $\left({ }^{1} \mathrm{H}-\mathrm{NMR}\right)$ spectroscopy. The effect of $\beta$ $\mathrm{CD}$ on the degradation of AMX in a $\mathrm{pH} 1.2$ solution was also investigated.

\footnotetext{
*e-mail: tokumura@iuhw.ac.jp
}

\section{EXPERIMENTAL}

Materials AMX was purchased from Sigma Chemical Company (St. Louis, Mo, USA). $\alpha$-Cyclodextrin $(\alpha-\mathrm{CD}), \beta-\mathrm{CD}$, and $\gamma-\mathrm{CD}$ were purchased from Wako Pure Chemical Industries, Ltd. Other chemicals were of reagent or HPLC-grade.

Solubility Studies Fifty milligrams of AMX was added to $5 \mathrm{ml}$ of $\beta$-CD solution at a concentration of $0.0,5,10,15$, or $20 \mathrm{mM}$. After being stored for 3 days to achieve equilibrium at $25^{\circ} \mathrm{C}$, the solutions were filtered through a membrane with mean pore size of $0.45 \mu \mathrm{m}$, and the concentration of AMX in the filtrate was determined by high performance liquid chromatography (HPLC). An apparent stability constant $\left(K^{\prime}\right)$ of the complex of AMX with $\beta$-CD was calculated from the following equation. ${ }^{10}$

$$
K^{\prime}=\frac{\text { Slope }}{S_{0}(1-\text { Slope })}
$$

NMR Spectroscopy This was conducted in $\mathrm{D}_{2} \mathrm{O}$ using a JNM LA500 (JEOL, Ltd.). ${ }^{1} \mathrm{H}$-Chemical shifts were given relative to external tetramethylsilane. The concentrations of AMX and CDs in sample solutions were $4 \mathrm{mM}$. 


\section{Measurement of Stability of AMX in a pH 1.2 So-} lution AMX was dissolved in a $\mathrm{pH} 1.2$ solution, the 1st fluid for dissolution test of Japanese Pharmacopoeia XV (JP XV), to make a $5 \mathrm{mg} / \mathrm{ml}$ solution. A $4.9 \mathrm{ml}$ aliquot of the $1 \mathrm{st}$ fluid for dissolution test of JP XV with or without CDs was pre-incubated for $15 \mathrm{~min}$ at 37,50 and $60^{\circ} \mathrm{C}$. The experiments were initiated by adding the AMX solution to produce a final concentration of $100 \mu \mathrm{g} / \mathrm{ml}$ that was $0.24 \mathrm{mM}$. A $100 \mu \mathrm{l}$ aliquot of the sample solution was removed at appropriate intervals. The solution was added to 200 $\mu \mathrm{l}$ of a $\mathrm{pH} 6.8$ buffer, the 2 nd fluid for disintegration test of JP XV, and mixed well. A $20 \mu \mathrm{l}$ volume of the solution was injected onto an HPLC column. In the comparison among CDs, the concentrations of $\alpha$-CD, $\beta$-CD and $\gamma$-CD were $1.2 \mathrm{mM}$. The molar ratio of AMX to the CDs was $1: 5$. In the experiment on the effect of the amount of $\beta$-CD added, the concentrations of $\beta$-CD used were $0.12,0.24,0.48,1.2$ and 2.4 $\mathrm{mM}(1: 0.5,1: 1,1: 2,1: 5$, and $1: 10$, respectively).

Determination of AMX by HPLC The concentration of AMX in a sample solution was determined by HPLC with a Model LC-9A pump, equipped with a Model SCL-6B system controller, a Model SPD-6A UV spectrophotometric detector, a Model CTO-6B column oven, a Model C-R4A Chromatopac; and a Model SIL-6B autoinjector, all from Shimadzu Corporation (Kyoto, Japan). The mobile phase was acetonitrile-water-perchloric acid $(60 \%)$-sodium perchlorate monohydrate $(128: 872: 1: 5, \mathrm{v} / \mathrm{v} / \mathrm{v} / \mathrm{w})$. The chromatographic column was an YMC Pack AM312 ODS $(150 \mathrm{~mm} \times 6 \mathrm{~mm}$ I.D., particle diameter $5 \mu \mathrm{m})$ obtained from YMC Co., Ltd. (Kyoto, Japan) .
The flow rate, the wavelength for determination, and the temperature of the column were $1 \mathrm{ml} / \mathrm{min}, 254$ $\mathrm{nm}$ and $40^{\circ} \mathrm{C}$, respectively.

\section{RESULTS AND DISCUSSION}

Evidence of Inclusion Complexation Table 1 shows the results of ${ }^{1} \mathrm{H}-\mathrm{NMR}$ spectroscopy. The position of each proton in the chemical structure of AMX is shown in Fig. 1. The effect of $\alpha$-CD on the chemical shifts of AMX was very small. In the case of $\beta$-CD, H5 showed a high-field shift. When $\gamma$-CD was added, almost all protons of AMX shifted to the high-field region. These results suggested that AMX could form inclusion complexes with $\beta$-CD and $\gamma$-CD.

Figure 2 shows the effect of $\alpha-\mathrm{CD}, \beta-\mathrm{CD}$ and $\gamma$-CD on the rate of degradation of AMX in the $\mathrm{pH} 1.2$ solution at $37^{\circ} \mathrm{C}$. In this experiment, the concentrations of AMX and CDs were 0.24 and $1.2 \mathrm{mM}$, respectively. Each plot in Fig. 2 is considered to be linear, which shows that the degradation of AMX under the conditions is a pseudo first-order reaction. The apparent first-order rate constant for each plot is summarized in Table 2. The rate constant of AMX was well

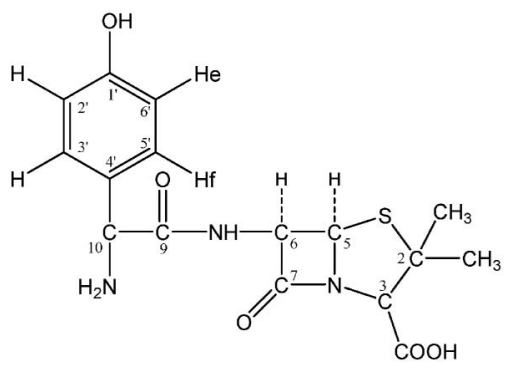

Fig. 1. Chemical Structure of AMX

Table 1. ${ }^{1} \mathrm{H}-\mathrm{NMR}$ Chemical Shifts of AMX in the Presence or Absence of CDs

\begin{tabular}{ccccccrr}
\hline \hline \multirow{2}{*}{ Proton } & \multicolumn{7}{c}{ Chemical shift (ppm) } \\
\cline { 2 - 8 } & AMX & $\begin{array}{c}\text { AMX } \\
+\alpha-\mathrm{CD}\end{array}$ & \multicolumn{1}{c}{$\Delta^{a)}$} & $\begin{array}{c}\text { AMX } \\
+\beta \text {-CD }\end{array}$ & $\Delta$ & $\begin{array}{c}\text { AMX } \\
+\gamma \text {-CD }\end{array}$ & $\Delta$ \\
\hline $2 \alpha-\mathrm{CH} 3$ & $1.203 \mathrm{~s}$ & 1.216 & 0.013 & 1.203 & 0.000 & 1.208 & 0.005 \\
$2 \beta-\mathrm{CH} 3$ & $1.228 \mathrm{~s}$ & 1.227 & -0.001 & 1.228 & 0.000 & 1.226 & -0.002 \\
$\mathrm{H} 3$ & $3.943 \mathrm{~s}$ & 3.948 & 0.005 & 3.943 & 0.000 & 3.942 & -0.001 \\
$\mathrm{H} 10$ & $4.903 \mathrm{~s}$ & 4.905 & 0.002 & 4.906 & 0.003 & 4.874 & -0.029 \\
$\mathrm{H} 5$ & $5.276 \mathrm{q}$ & 5.278 & 0.002 & 5.259 & -0.017 & 5.258 & -0.018 \\
$\mathrm{H} 6$ & $5.301 \mathrm{q}$ & 5.302 & 0.001 & 5.317 & 0.016 & 5.300 & -0.001 \\
$\mathrm{eH}$ & $6.770 \mathrm{q}$ & 6.772 & -0.002 & 6.772 & 0.002 & 6.766 & -0.004 \\
$\mathrm{fH}$ & $7.161 \mathrm{q}$ & 7.163 & 0.002 & 7.163 & 0.002 & 7.157 & -0.004 \\
\hline
\end{tabular}

a) Change of chemical shifts, calculated from (a chemical shift of AMX with CDs-that of AMX without CDs). 


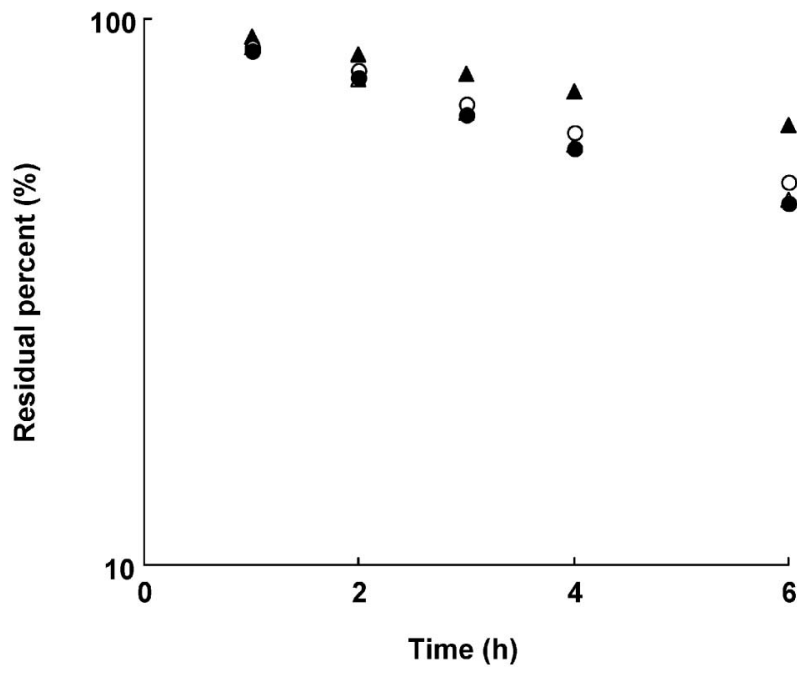

Fig. 2. Effect of CDs on the Degradation of AMX in the Solution of $\mathrm{pH} 1.2$ at $37^{\circ} \mathrm{C}$

๑; AMX alone, $\triangle ; \alpha$-CD, $\boldsymbol{\Delta} ; \beta$-CD, $\bigcirc ; \gamma$-CD.

Table 2. Effect of CDs on the Degradation of AMX in $\mathrm{pH} 1.2$ Solution at $37^{\circ} \mathrm{C}$

\begin{tabular}{ccc}
\hline \hline & $\mathrm{k}\left(\mathrm{h}^{-1}\right)$ & $\mathrm{t}_{1 / 2}(\mathrm{~h})$ \\
\hline $\mathrm{AMX}$ & 0.1316 & 5.27 \\
$\mathrm{AMX}: \alpha-\mathrm{CD}=1: 5^{a)}$ & 0.1288 & 5.38 \\
$\mathrm{AMX}: \beta-\mathrm{CD}=1: 5$ & 0.0757 & 9.17 \\
$\mathrm{AMX}: \gamma-\mathrm{CD}=1: 5$ & 0.1164 & 5.95 \\
\hline
\end{tabular}

Each value is calculated from a set of data. The initial concentration of AMX is $100 \mu \mathrm{g} / \mathrm{ml}(0.24 \mathrm{mM})$. a) The initial molar ratio in the solution.

consistent with values previously reported. ${ }^{11,12)}$ It was found from these results that $\alpha$-CD had no stabilizing effect on AMX, and that $\beta$-CD had a stronger effect than $\gamma$-CD.

CDs have been reported to suppress or enhance chemical reactions in aqueous solutions by forming inclusion complexes. ${ }^{5,13,14)}$ The degradation rate for AMX in the acidic solution was decreased by the addition of $\beta$-CD and $\gamma-\mathrm{CD}$, indicating that inclusion complexes of AMX with $\beta$-CD and $\gamma$-CD formed in the solution. These results were supported by those of ${ }^{1} \mathrm{H}-\mathrm{NMR}$ spectroscopy. Therefore, the complex of AMX and $\beta$-CD was studied using a solubility method. Figure 3 shows an equilibrium phase solubility diagram for the AMX/ $\beta$-CD system in water. The solubility of AMX increased from 5.88 to $7.09 \mathrm{mM}$ with the addition of $\beta$-CD from 0 to $20 \mathrm{mM}$ showing a linear relationship. The apparent stability constant, $K^{\prime}$, of the complex in water at $25^{\circ} \mathrm{C}$ was estimated as $10.72 \mathrm{M}^{-1}$ from the straight line.

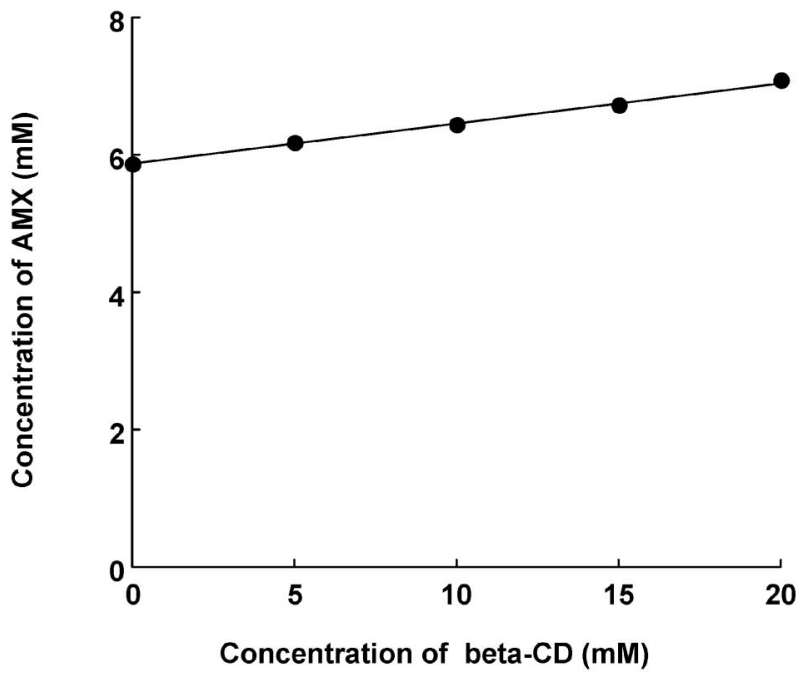

Fig. 3. Effect of Concentrations of $\beta$-CD on the Solubility of AMX in Water at $25^{\circ} \mathrm{C}$

Effect of $\beta$-CD Concentration and Temperature on the Degradation of AMX AMX is unstable in acidic solution, therefore a proton pump inhibitor is inevitably used for the eradication therapy. Improving the stability of AMX is considered important, so further investigation with $\beta$-CD was performed.

Figure 4 shows the effect of the concentration of $\beta$ $\mathrm{CD}$ on the degradation of AMX in a solution of $\mathrm{pH}$ 1.2 at 37,50 and $60^{\circ} \mathrm{C}$. Each plot was linear, which shows that the degradation is a pseudo first-order reaction. The apparent first-order rate constant was calculated from this relationship. The apparent firstorder rate constants are summarized in Table 3 . The rate constants of AMX alone and $\mathrm{AMX}: \beta-\mathrm{CD}=1$ : 5 in Table 3 were smaller than those in Table 2 . This difference was considered to be caused by the different final sampling time in the experimental conditions, which were $6 \mathrm{~h}$ for the experiment of Table 2 and $8 \mathrm{~h}$ for that of Table 3 . The ratios of the rate constant, AMX : $\beta$-CD $=1: 5 /$ AMX alone, in Tables 2 and 3 were about 0.6 , which indicated that the relative relationship was maintained between the data in Tables 2 and 3. The stabilizing effect of $\gamma$-CD was confirmed from this relationship, although the effect was not detected by the comparison of the rate constant between AMX $: \gamma-\mathrm{CD}=1: 5$ in Table 2 and AMX alone in Table 3.

When $\beta$-CD was present in the reaction system, the apparent first-order rate constant, $\mathrm{k}$, was smaller at all three temperatures as shown in Table 3. The results indicate that the stabilizing effect increased 

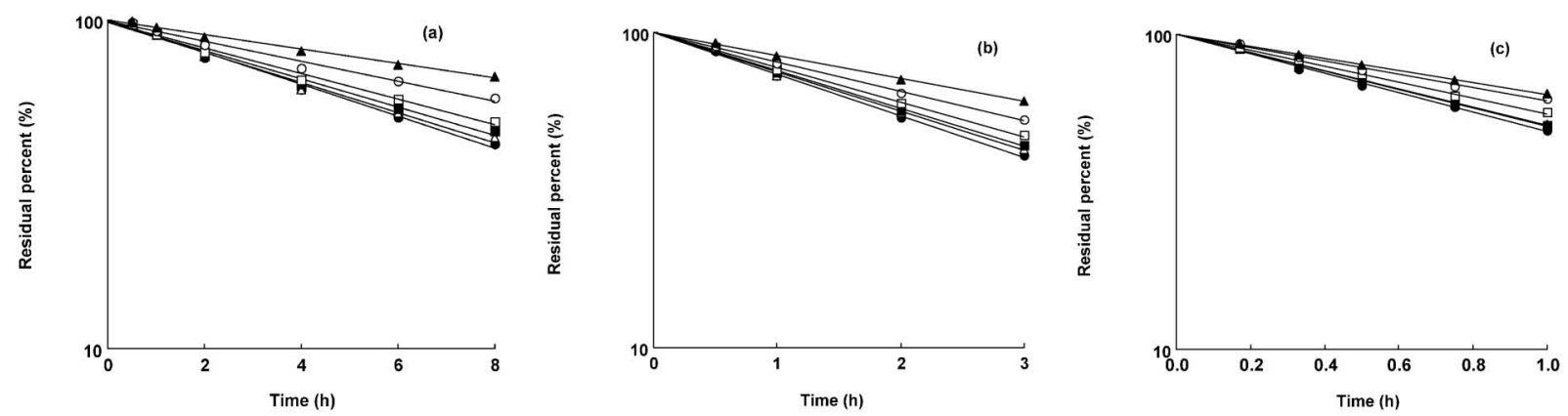

Fig. 4. Effect of Concentrations of $\beta$-CD on the Degradation of AMX in the Solution of pH 1.2 at 37 (a), 50 (b), and $60^{\circ} \mathrm{C}$ (c) -; AMX alone, $\triangle$; $\mathrm{AMX}: \beta-\mathrm{CD}=1: 0.5$, $\mathbf{\square}$, $\mathrm{AMX}: \beta-\mathrm{CD}=1: 1, \square$; $\mathrm{AMX}: \beta$ - $\mathrm{CD}=1: 2, \mathrm{O}$; $\mathrm{AMX}: \beta$ - $\mathrm{CD}=1: 5, \boldsymbol{\Delta} ; \mathrm{AMX}: \beta$ - $\mathrm{CD}=1: 10$.

Table 3. Effect of Concentrations of $\beta$-CD on the Apparent First-order Rate Constants of the Degradation of AMX in $\mathrm{pH} 1.2$ Solution at $37^{\circ} \mathrm{C}, 50^{\circ} \mathrm{C}$, and $60^{\circ} \mathrm{C}$

\begin{tabular}{|c|c|c|c|c|c|c|}
\hline \multirow{3}{*}{$\mathrm{AMX}: \beta-\mathrm{CD}^{a)}$} & \multicolumn{6}{|c|}{$\mathrm{k}\left(\mathrm{h}^{-1}\right)$} \\
\hline & \multicolumn{2}{|c|}{$37^{\circ} \mathrm{C}$} & \multicolumn{2}{|c|}{$50^{\circ} \mathrm{C}$} & \multicolumn{2}{|c|}{$60^{\circ} \mathrm{C}$} \\
\hline & Mean & SD & Mean & SD & Mean & SD \\
\hline AMX alone & 0.1121 & 0.0013 & 0.3021 & 0.0019 & 0.7126 & 0.0653 \\
\hline $1: 0.5$ & 0.1051 & 0.0007 & 0.2871 & 0.0020 & 0.6658 & 0.0117 \\
\hline $1: 1$ & 0.0992 & 0.0002 & 0.2764 & 0.0040 & 0.6763 & 0.0149 \\
\hline $1: 2$ & 0.0893 & 0.0028 & 0.2530 & 0.0043 & 0.5809 & 0.0219 \\
\hline $1: 5$ & 0.0697 & 0.0007 & 0.2148 & 0.0018 & 0.4897 & 0.0096 \\
\hline $1: 10$ & 0.0509 & 0.0010 & 0.1686 & 0.0027 & 0.4410 & 0.0070 \\
\hline
\end{tabular}

Each value represents the mean and S.D. of 3 determinations. The initial concentration of AMX in the solution is $100 \mu \mathrm{g} / \mathrm{ml}(0.24 \mathrm{mM}) . a$ ) Initial molar ratio in the solution.

Table 4. Effect of the Concentration of $\beta$-CD on the Activation Energy for the Degradation of AMX in the Solution at pH 1.2

\begin{tabular}{cc}
\hline \hline $\mathrm{AMX}: \beta-\mathrm{CD}^{a)}$ & $\mathrm{Ea}(\mathrm{J} / \mathrm{mol})$ \\
\hline AMX alone & $6.9 \times 10^{4}$ \\
$1: 1$ & $7.1 \times 10^{4}$ \\
$1: 5$ & $7.3 \times 10^{4}$ \\
$1: 10$ & $8.0 \times 10^{4}$ \\
\hline
\end{tabular}

a) Initial molar ratio in the solution.

with the concentration of $\beta$-CD in the system.

Figure 5 shows Arrhenius plots of the degradation of AMX with or without $\beta$-CD. All plots showed good linearity. The activation energy of the degradation was calculated from the slope of each plot. The results are shown in Table 4.

AMX, which is unstable in acidic solution, was found to be stabilized in the presence of $\beta$-CD. It was indicated from our results that the stabilizing effect of

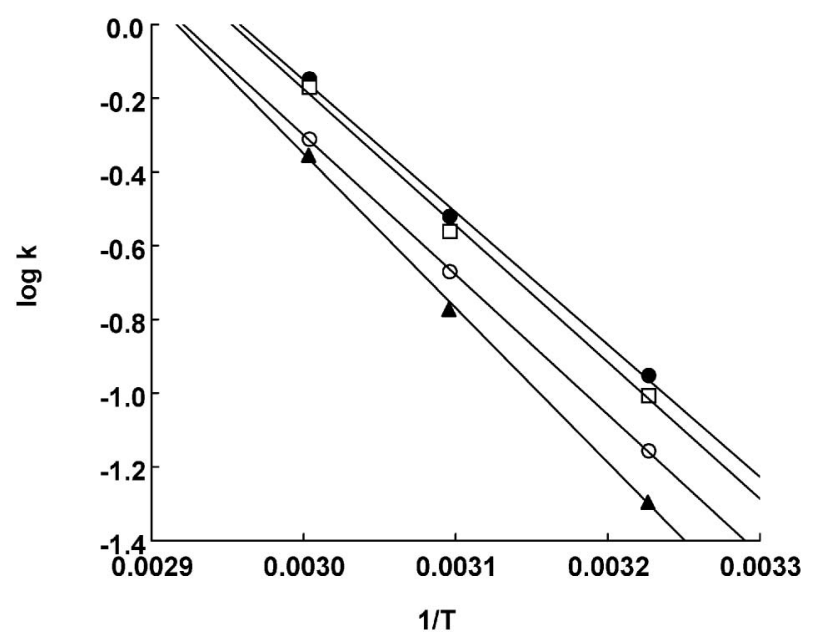

Fig. 5. Arrhenius Plots Based on the Rate Constants Measured in the Solution at $\mathrm{pH} 1.2$

○; $\mathrm{AMX}$ alone, $\square$; $\mathrm{AMX}: \beta-\mathrm{CD}=1: 1, \bigcirc$; $\mathrm{AMX}: \beta-\mathrm{CD}=1: 5, \boldsymbol{\Delta}$; $\mathrm{AMX}: \beta-\mathrm{CD}=1: 10$.

$\beta$-CD dependeds on the formation of an inclusion complex. These results should be useful for designing dosage forms of AMX.

\section{REFERENCES}

1) Patel V. R., Amiji M. M., Pharm. Res., 13, 588-593 (1996).

2) Tokumura T., Machida Y., J. Control. Release, 110, 581-586 (2006).

3) Uekama K., Yakugaku Zasshi, 124, 909-935 (2004).

4) Tokumura T., Ueda H., Tsushima Y., Kasai M., Kayano M., Amada I., Nagai T., Chem. Pharm. Bull., 32, 4179-4184 (1984).

5) Tokumura T., Tatsuishi K., Kayano M., Machida Y., Nagai T., Chem. Pharm. Bull., 33, 2079-2083 (1985).

6) Muraoka A., Tokumura T., Machida Y., Eur. 
J. Pharm. Biopharm. 58, 667-671 (2004).

7) Tomono K., Goto H., Suzuki T., Ueda H., Nagai T., Abstracts of papers, the 119th Annual Meeting of the Pharmaceutical Society of Japan, Tokushima, March 1999, No. 4, p. 23.

8) Tomono K., Ueda H., Nagai T., Goto H., Suzuki T., JP Patent Hei 11-232488 (1999).

9) Etoh S., Pharmaceutical Bulletin of Fukuoka University, 9, 167-168 (2009) .

10) Higuchi T., Connors K. A., "Advance in Analytical Chemistry and Instrumentation," ed. by Reilly C. N., Interscience, New York, 1965, pp. 117-212.

11) Erah P. O., Goddard S. F., Barrett D. A., Shaw P. N., Spiller C., J. Antimicrob. Chemother., 39, 5-12 (1997).

12) Tokumura T., Machida Y., Int. J. Pharm., 228, 1-4 (2001).

13) Uekama K., Yakugaku Zasshi, 101, 857-873 (1981).

14) Uekama K., Yakugaku Zasshi, 124, 909-935 (2004). 